Dhaka Univ. J. Biol. Sci. 25(2): 97-102, 2016 (July)

\title{
THE EFFECTIVENESS OF PSYCHO-EDUCATION TO INCREASE KNOWLEDGE AND PARENTING PRACTICES IN CAREGIVERS OF CHILDREN WITH AUTISM
}

\author{
Jesan Ara ${ }^{1}$ and Kamal Uddin Ahmed Chowdhury \\ Department of Clinical Psychology, University of Dhaka, Dhaka-1000, Bangladesh \\ Key words: Psycho-education, Parenting practices, Caregivers, Autism
}

\begin{abstract}
An attempt was made to see the impact of psycho-education to increase knowledge and parenting practices in caregivers of children with autism. A total of 40 caregivers (20 in experimental group and 20 in control group) of children with autism participated in this study. Pre-post research design was used to assess the concept about autism and parenting practices of the participants. Caregivers of the experimental group received a psycho-educational session and the control group did not receive the psycho-education session. The psychoeducational program consisted of three sessions held during three weeks (two hours in each week). The results were discussed in terms of clinical significance. Compared with the control group, the experimental group showed improvement in parenting practices and knowledge about autism both immediately after intervention.
\end{abstract}

\section{Introduction}

Autism spectrum disorders (ASD) refers to a wide variety of complex developmental disorders that typically appear during the 3 years of life ${ }^{(1)}$. A research done in Shishu Bikash Kendra, Bangladesh (SBK or Child Development Centre); found that one fourth was referred for assessment of autism spectrum disorders (ASD) (23\%). They also found that commonest psychiatric diagnosis was Hyperkinetic Disorders $(33 \%)$ followed by Autism Spectrum Disorders and other Pervasive Developmental Disorders (PDD) $(29 \%)^{(2)}$.

Families in Bangladesh are the basic units of social security for any citizen irrespective of disability. Parents and family members have been involved in the basic care of their children with disability. Care for children with ASD is often challenging and distressing for caregivers. A number of confusions and misconceptions about ASD exist among them. Psycho-education for family of caregivers of young children and also severely mentally ill clients proved to be an effective option. The term psycho-education

*Author for correspondence: <jesan53006@gmail.com> 
comprises systemic, didactic psycho-therapeutic interventions, which are adequate for educating and informing patients and their relatives about the illness and its attainment; facilitating both an understanding and personal responsibility of handling the illness and supporting those afflicted in coping with the disorder ${ }^{(3)}$.

Psycho-education enables family members to make informed treatment decisions about the child; reduce anxiety about the illness; and help families to cope with the illness and its complications. Randomized and controlled studies suggest that parent training leads to reduced maternal depression, improved maternal knowledge of autism and communication style, and improved child communicative behavior ${ }^{(4)}$. A recent study was found to have positive outcomes from psycho-education programs for children with a psychiatric illness ${ }^{(5)}$. There is empirical evidence that parent training contributes to the effectiveness of behavioral treatments and, for example, enhances functional communication in young children with autism and may result in improved parent-child interactions after pivotal response training(6,7).

It is evident that in Bangladesh mothers of retarded children have unrealistic expectations and pressurize the child to behave normally and finally become frustrated when their children fail to meet their demand ${ }^{(8)}$. Understanding of the condition probable reasons and long term effects of problem behavior could be helpful in reducing caregivers' confusions and level of distress. Hence, caregivers need basic education about the condition and long-term effects of the same. Similarly, caregivers of children with autism need information on causes of autism, management and coping skills, and understanding of the reasons. The study aims to develop a readily available psycho education material on autism and see its effective use as a way to support caregiver of children with autism.

\section{Materials and Methods}

Initially 40 caregivers of children with autism were purposively selected from two special schools of autism. The caregivers were matched according to age, sex, education, income, structure of family, etc. and were divided according to pre-test score into two groups - the experimental group (20), and the control group (20). The demographic characteristic of the participants is given in Table 1.

The Autism Concept Questionnaire was used to assess the caregivers' concept of factual information about autism. It contains 23 multiple choice items taping concepts such as meaning, causes, features, special education and treatment of autism. The highest possible score is 23. Each question has four alternative answers where there is only one correct answer. The participants were instructed to choose one answer for each question.

The Bengali version of parenting practices scale was used to assess the participants' parenting skills. This scale was originally developed(9). The scale contains 34 multiplechoice items. The score range of this scale is 0 - 190. The reliability of the Bengali version 
of the scale was determined by i.e., administering both the version to a target sample with two weeks interval. The correlation co-efficient e.g., Pearson $r$ was found to be $r=$ 0.70. The original English version scale was found to have a six-month test-retest reliability of $r=0.70$ and an internal consistency coefficient alpha of $0.799^{(9)}$.

Psycho-education material (in Bangla) used in this study was developed by the researcher herself. It contained areas with - a general introduction on autism, i.e. common symptoms, the etiology, available treatment, prognosis, information about food, daily activity, recreational activity, task analysis, how to behave with these children, what should be done if child becomes violent and demanding or calm, uses of reinforcement, how to manage while looking after the child, understanding their situation, how to provide them with support.

Table 1. Baseline characteristics of the participants.

\begin{tabular}{|c|c|c|c|}
\hline & \multirow[t]{2}{*}{ Characteristics } & $\begin{array}{l}\text { Experimental group } \\
\qquad(\mathrm{n}=20)\end{array}$ & $\begin{array}{l}\text { Control group } \\
(\mathrm{n}=20)\end{array}$ \\
\hline & & Frequency (\%) & Frequency (\%) \\
\hline \multirow[t]{3}{*}{ Age } & 18 - 28 years & $1(5)$ & $2(10)$ \\
\hline & $29-39 "$ & $11(55)$ & $11(55)$ \\
\hline & $40-49 \quad "$ & $8(40)$ & $7(35)$ \\
\hline \multirow[t]{3}{*}{ Education } & Below SSC & $1(5)$ & $0(0)$ \\
\hline & SSC-HSC & $3(15)$ & $4(20)$ \\
\hline & Graduate - Post-graduate & $16(80)$ & $16(80)$ \\
\hline \multirow{4}{*}{$\begin{array}{l}\text { Family } \\
\text { income }\end{array}$} & Below 10,000 Tk & $1(5)$ & $1(5)$ \\
\hline & 10001 to $20000 \mathrm{Tk}$ & $2(10)$ & $2(10)$ \\
\hline & 20001 to $40000 \mathrm{Tk}$ & $13(65)$ & $12(60)$ \\
\hline & $40001 \mathrm{Tk}$ to above & $4(20)$ & $5(25)$ \\
\hline
\end{tabular}

An official permission from relevant authority was obtained. Informed consent letters were signed by the participants. Data collection was conducted from May to August, 2012 in official settings of the selected schools. Forty caregivers initially completed the self-administered measuring instruments. The caregivers assigned to the experimental group received a psycho-educational intervention after the pre-test whilst the caregivers assigned to the control group did not receive any specific intervention but tested again after specified time. The psycho-education comprised of three sessions of two hours duration (6 hours) for each caregiver separately. Printed materials were provided as a part of psycho-education. A dairy was also maintained for each participant to record progression of the intervention programme. After four weeks of completing the psycho-education session the participants were again interviewed and all measures 
were re-administered. During the whole process, comforts of the patients were taken into consideration and at the end of the study the caregivers were thanked for their active involvement.

\section{Results and Discussion}

In order to investigate the impact of psycho-education on caregivers of children with autism, paired comparison t-test was used to determine the significant differences between two groups under both pre- and post test condition. P-values less than 0.05 were considered to indicate statistical significance.

Table 2. Comparison between the means of obtained scores from the pre-test session.

\begin{tabular}{|c|c|c|c|c|c|c|}
\hline \multirow[t]{2}{*}{ Variable } & \multirow{2}{*}{$\begin{array}{c}\text { Maximum } \\
\text { possible } \\
\text { score }\end{array}$} & \multicolumn{2}{|c|}{$\begin{array}{l}\text { Experimental } \\
\text { group }\end{array}$} & \multicolumn{2}{|c|}{$\begin{array}{l}\text { Control } \\
\text { group }\end{array}$} & \multirow[t]{2}{*}{$\mathrm{t}$ value } \\
\hline & & Mean & $\mathrm{Sd}$ & Mean & $\mathrm{Sd}$ & \\
\hline Autism concept questionnaire & 23 & 10.80 & 3.33 & 11.75 & 2.83 & 0.99 \\
\hline Parenting practice scale & 190 & 111.75 & 26.17 & 115.35 & 18.58 & 0.45 \\
\hline
\end{tabular}

$\mathrm{T}$ test values for pre test session present in Table 2 showed no significant difference in concepts of autism and parenting practices between experimental and control group. But in the post test comparison significant differences at $p<0.001$ level was found between the two groups of both variables (Table 3).

Table 3. Comparison between the means of obtained scores from the post-test session.

\begin{tabular}{|c|c|c|c|c|c|c|}
\hline \multirow[t]{2}{*}{ Variable } & \multirow{2}{*}{$\begin{array}{c}\text { Maximum } \\
\text { possible } \\
\text { score }\end{array}$} & \multicolumn{2}{|c|}{$\begin{array}{l}\text { Experimental } \\
\text { group }\end{array}$} & \multicolumn{2}{|c|}{$\begin{array}{l}\text { Control } \\
\text { group }\end{array}$} & \multirow[t]{2}{*}{$t$ value } \\
\hline & & Mean & $\mathrm{Sd}$ & Mean & $\mathrm{Sd}$ & \\
\hline $\begin{array}{l}\text { Autism concept } \\
\text { questionnaire (ACQ) }\end{array}$ & 23 & 19.50 & 3.05 & 12.70 & 3.40 & $7.05^{* * *}$ \\
\hline $\begin{array}{l}\text { Parenting practice } \\
\text { scale (PPS) }\end{array}$ & 190 & 151.05 & 16.34 & 118.10 & 19.35 & $5.24^{* * *}$ \\
\hline
\end{tabular}

***Indicates significance at $\mathrm{p}<0.001 \%$ level.

As expected, the caregivers' concept about autism of the experimental group significantly improved after following intervention [ $t(20)=7.05, p<0.001]$. Significant improvements were also reported in case of parenting practices [ $t(20)=5.24, p<0.001]$.

The aim of this study was to test the efficacy of psycho-educational intervention in increasing knowledge regarding the condition of the parents of children with autism spectrum disorders. The results were largely positive with significant change found in most areas of knowledge as a function of intervention of the experimental group and no change as a function of the control group (Table 3). 
The present study has demonstrated that psycho-education is needed to dispel the misconceptions such as "medication is not effective for ASD" "ASD is a mental disorder" "social, communication and behavioral symptoms develop due to the lack of parental skill" in order to increase the effectiveness of intervention. The findings of a study has suggested that engaging families collaboratively, sharing illness information, suggesting behaviors that promote recuperation, and teaching coping strategies that reduce the families' sense of burden contribute to the effectiveness of handling children with ASD's(10). Changes in caregivers' knowledge as a result of participating in a psychoeducational intervention had been directly evaluated by the researchers ${ }^{(11,12)}$. The findings of this study are also in conformity with previous studies(13,14).

Another aim of the present study was to assess the impact of this psychoeducational intervention on caregivers parenting practices. Summarizing the main findings, the intervention group in comparison to the control group reported more positive parenting behavior. The caregivers in this study did express frustration and helplessness in managing their children's difficult behaviors. They appeared to be actively seeking help with caregiving rather than just information. This is confirmed by the fact that the mean of post-intervention scores on the Parenting Practices Scale (PPS) were 151.05 of the experimental group in contrast to the control group where the mean scores were 118.10 (Table 3). The caregivers reported positive interactions with child, interactions rated as happier, the caregivers were more interested in the interaction, the interaction was less stressful, and the communication style was more positive. The findings of the present study are also confirmed by recent research findings on evaluation of an intervention system for families of children with disabilities ${ }^{(15)}$. The findings of this study are also in conformity with some other studies which reported a buffering effect of positive parenting practices on child outcomes, even in at-risk ${ }^{(16)}$.

Several studies show the effectiveness of intervention increases when parents of autistic children are treated as co-therapists and advocates in therapy ${ }^{(17,18)}$. Similarly present findings strongly support the need for parental training through psychoeducational intervention. The children whose caregivers attended psycho-educational intervention felt empowered by the information and were able to view their children's behavior more normatively and with less frustration. The present study concludes that psycho-educational intervention is effective in providing information regarding caregivers' needs in dispelling the misconception about children with autism spectrum disorders and it is also effective in enhancing positive parenting style.

\section{References}

1. American Psychiatric Association 2000. Diagnostic and Statistical Manual of Mental Disorders, Fourth Edition - Text Revision (DSM-IV-TR). Washington, DC: American Psychiatric Publishing. 
2. Islam F, Parveen $M$ and Parvin R 2011. Child psychiatric disorders presenting to a tertiary multidisciplinary child development service in Bangladesh. Bangladesh J. Child Health $35(3)$.

3. Oshima I 1993. Psycho-education. In: New Psychiatry Dictionary (Kato M. Ed.), p. 414. Kobundo, Tokyo.

4. McConachie H and Diggle T 2007. Parent implemented early intervention for young children with autism spectrum disorder : A systematic review. J. Eva. Cli. Prac. 13: 120-129.

5. Gearing RE 2008. Evidence-based family psycho-eduational interventions for children and adolescents with psychotic disorders. J. Can. Child and Adol. Psychat. 17: 2-11.

6. Schreibman L 2000. Intensive behavioral/psycho-educational treatments for autism: Research needs and future directions. J. Aut. Dev. Disord. 30: 373-378.

7. Moes D and Frea W 2002. Contextualized behavioral support in early intervention for children with autism and their families. J. Aut. Dev. Disord. 35: 519-533.

8. Zaaman S S and Rahman N 1982. A comparative study of attitudes and personality traits of mothers of mentally retarded children with and without intervention. Dhaka Univ. J. Psychol. 12: 33-49.

9. Begum R, Rahman N and Ahmed M 2003. Impact of psycho-education and support programme for parents of children with intellectual disability. University of Dhaka, Bangladesh, (Unpublished thesis).

10. Gillberg C, Stenffenburg S and Schaumann H 1991. Is autism more common now than ten years ago? Brit. J. Psychiat. 158: 403-409.

11. Cameron C, Wilby A, Gavidia-Payne S, Hudson A, Matthews J, Nankervis K and Radler G 1999. Strategies and supports used by parents in dealing with their children with an intellectual disability. Paper presented at the 34th Annual Conference of the Australian Psychological Society, Hobart.

12. Landy S and Tam KK 1996. Yes, parenting does make a difference to the development of children in Canada. In: Growing Up in Canada: National Longitudinal Survey of Children and Youth. Human Resources Development Canada and Statistics Canada.

13. Peshawaria R and Menon DK 1991. Working with the families of children with mental handicap in India : Various models. Coun. Psychol. Quar. 4(4).

14. Kuhn JC and Carter AS 2006. Maternal self-efficacy and associated parenting cognitions among mothers of children with autism. Amer. J. Orthopsychiatry 76: 564-575.

15. Marcus L, Lansing M, Andrews $C$ and Schopler E 1978. Improvement of teaching effectiveness in parents of autistic children. J. Am. Aca. Child Psych. 17: 625-639.

16. Patterson SY, Smith V and Mirenda P 2012. A systematic review of training programs for parents of children with autism spectrum disorders: Single subject contributions. [Epub ahead of print]

17. Bristol and Wiegerink R 1979. Parent involvement. In: Autism: A practical guide for parents and professional (Paluszny M J Eds.), New York: Syracuse University Press.

18. Schopler E 1984. My great teachers. In: The effects of autism on the family (Schopler E \& G B Mesibov Eds.), pp. 227-232. New York: Plenum. 